\title{
The Effect of Temperature on Polycyclic Aromatic Hydrocarbon Persistence in an Unacclimated Agricultural Soil
}

\author{
MERVIN P. COOVER and RONALD C. SIMS \\ Utah Water Research Laboratory and \\ Department of Civil and Environmental Engineering \\ Utah State University \\ Logan, UT 84322-8200
}

\section{ABSTRACT}

A laboratory study was conducted to investigate the effect of temperature on the persistence of polycyclic aromatic hydrocarbons (PAHs) incubated in an unacclimated agricultural sandy loam soil. Soil microcosms were spiked with 16 priority pollutant PAHs and placed in incubation chambers at 10,20, and $30^{\circ} \mathrm{C}$. Triplicate sets of microcosms at each temperature were periodically removed from incubation over the 240 day study period and solvent extracted. Concentrations of PAHs in the soil were determined by HPLC analysis of the extracts. Substantial loss of three-ring compounds was observed at all temperatures whereas there was very little apparent loss of five and six-ring compounds at any temperature. The estimated half lives of acenaphthene, fluorene, and phenanthrene were comparable to values reported in the literature, but all other PAHs were more recalcitrant than reported in the literature. Increasing the soil temperature significantly improved the rate and extent of apparent loss of low molecular weight PAHs but had little effect on loss of five and six-ring PAHs. The effect of temperature on first order rate coefficients for loss of fluorene and on zero order rate coefficients for loss of anthracene, fluoranthene, pyrene and benz[a] anthracene was characterized by the Arrhenius equation but for the remaining compounds the Arrhenius equation was not useful. For land treatment of hazardous wastes containing PAHs, measures should be investigated to ensure loss of the more recalcitrant PAHs during the active treatment period and management options should be developed to ensure continued loss of PAHs during closure of a land treatment site when waste applications have ceased.

\section{INTRODUCTION}

The proper design and management of a hazardous waste land treatment system requires an understanding of the rates at which hazardous constituents of an applied waste are degraded. With knowledge of degradation rates in conjunction with toxicity and mobility assessments the application rate and frequency of waste reapplication to a land treatment system may be determined [1]. In addition, soil management options for enhancing treatment are assessed, in part, by evaluating the influence of potential options on the rate of constituent 
degradation [1]. U.S. Environmental protection Agency regulations address the importance of understanding constituent degradation rates by stipulating that, before a full scale operational permit can be issued, a treatment demonstration program be conducted to identify measures for enhancing degradation, transformation, and immobilization of hazardous constituents [2].

The evaluation of degradation kinetics for constituents of a complex waste to be land treated consists of observing apparent loss of the parent compound from soil as a function of time [1]. For most nonvolatile organic wastes the principal treatment mechanism in soils is believed to be biodecomposition $[3,4,5]$ although the contribution of abiotic loss mechanisms cannot necessarily be ignored $[4,6]$. The complexity of the soil environment, the effects of environmental parameters, and the influence of microbial population and distribution dynamics on biotic decomposition processes renders the mechanistic interpretation and modeling of soil degradation kinetics difficult. This difficulty has led to the practice of applying simple empirical models to the evaluation of apparent loss and mineralization kinetics. The use of first order decay expressions has, in some cases, been found to be adequate for describing apparent loss kinetics $[3,5,7]$ and is generally the model of choice for the design and management of land treatment systems. First order or other simple decay expressions must be used with caution, however, as they do not always apply and have the potential of leading to inaccurate estimates of the rate and extent of degradation $[6,8]$.

Temperature and soil moisture are frequently the decisive climatic factors influencing rates of decomposition in soils [9]. Land treatment regulations stipulate that the climatic conditions of the intended treatment site be taken into account when establishing environmental conditions for required demonstration studies [2]. The Arrhenius expression has been used to characterize the effect of temperature on the degradation and mineralization of some compounds in soils $[8,10,11]$, but exceptions have been observed [8]. Use of the expression must therefore be justified on a case-by-case basis. The purpose of this study was to characterize the influence of temperature on the apparent loss kinetics of 16 priority pollutant polycyclic aromatic hydrocarbons (PAHs) in an unacclimated agricultural soil. These compounds were studied because of their presence in organic wastes that are either currently land treated or that are being considered for land treatment $[7,12]$ and because of the associated public health implications [13].

\section{MATERIALS AND METHODS}

\section{Aporeach}

Soil microcosms were prepared in glass beakers, spiked with a standard solution of 16 PAHs, and placed in incubation chambers at either 10,20, or $30^{\circ} \mathrm{C}$. To prevent low soil moisture from adversely affecting microbial populations the moisture content of the microcosm soils was maintained between 80 and $100 \%$ of the soil water holding capacity through regular additions of water. Periodically, triplicate sets of microcosms at each temperature were removed from incubation and solvent extracted. Concentrations of PAHs in the soil were determined by HPLC analysis of the extracts. The study was terminated after 240 days of incubation.

Soil concentrations of PAHs selected for study were approximately equal to the concentrations which would have been obtained had the soil been amended to a level of 1 응 by weight with a waste creosote sludge. This selection of $\mathrm{PAH}$ concentrations was based on the desire to complement simultaneous studies, conducted at the Utah water Research Laboratory (Logan, Utah), of PAH degradation in the same soil to which a complex hydrocarbon substrate in the form of waste creosote sludge had been added. Acute toxicity bioassay studies demonstrated that a $1 \%$ by weight concentration of creosote sludge in the selected soil was nontoxic to the soil microbiota [12]. 
A solution of all 16 PAHs was prepared in HPLC grade dichloromethane for addition to soil microcosms. All compounds were $98 \%$ pure or better and were obtained from Aldrich Chemical Co. (Milwaukee, WI) and Foxboro Co. (North Haven, CT). Properties of the compounds used are presented in Table 1 along with the soil concentrations that resulted following the addition of $2 \mathrm{~mL}$ of the spiking solution to $20 \mathrm{~g}$ soil microcosms.

PAHs of $99 \%$ purity obtained from the Foxboro Company (North Haven, CT) were used to prepare analytical standards in HPLC grade acetonitrile for HPLC analysis.

TABLE 1

Properties and Soil Concentrations of PAHs Used in the Degradation Study

\begin{tabular}{|c|c|c|c|c|c|}
\hline \multirow{2}{*}{ Compound } & $\begin{array}{l}\text { Number } \\
\text { of Fused } \\
\text { Bings } \\
\end{array}$ & \multicolumn{2}{|c|}{$\begin{array}{c}\text { Vapor } \\
\text { Pressure } \\
\text { e } 20^{\circ} \mathrm{C} \\
\text { (torr) }\end{array}$} & \multirow{2}{*}{$\begin{array}{l}\text { Aqueous } \\
\text { Solubility } \\
\frac{(\mu g / 1)}{30000}\end{array}$} & \multirow{2}{*}{$\begin{array}{c}\text { Soil } \\
\text { Concentration } \\
(\mu g / g) \\
501\end{array}$} \\
\hline & 2 & 4.92 & $\times 10^{-2}$ & & \\
\hline Acenaphthylene & 3 & 2.0 & $\times 10^{-2}$ & 3470 & 30.4 \\
\hline Acenaphthene & 3 & 2.9 & $\times 10^{-2}$ & 3930 & 400 \\
\hline Eluorene & 3 & 1.96 & $\times 10^{-2}$ & 1980 & 100 \\
\hline Phenanthrene & 3 & 6.80 & $\times 10^{-4}$ & 1290 & 1000 \\
\hline Anthracene & 3 & 1.3 & $\times 10^{-4}$ & 73 & 600 \\
\hline Fluoranthene & 4 & 6.0 & $\times 10^{-6}$ & 260 & 400 \\
\hline Pyrene & 4 & 6.85 & $\times 10^{-7}$ & 135 & 400 \\
\hline Benz [a] anthracene & 4 & 5.0 & $\times 10^{-9}$ & 14 & 30.1 \\
\hline Chrysene & 4 & 6.3 & $\times 10^{-7}$ & 2 & 200 \\
\hline Benzo[b] fluoranthene & 5 & 5.0 & $\times 10^{-7}$ & 1.2 & 9.94 \\
\hline Benzo[k] fluoranthene & 5 & 5.0 & $\times 10^{-7}$ & 0.55 & 9.98 \\
\hline Benzo[a]pyrene & 5 & 5.0 & $\times 10^{-7}$ & 3.8 & 10.76 \\
\hline Dibenz $[a, h]$ anthracene & 5 & 1.0 & $x 10^{-10}$ & 2.49 & 10.56 \\
\hline Benzo $[g, h, i]$ perylene & 6 & 1.0 & x $10^{-10}$ & 0.26 & 9.96 \\
\hline Indeno $[1,2,3-c, d]$ pyrene & 6 & 1.0 & $\times 10^{-10}$ & 62 & 5.26 \\
\hline
\end{tabular}

1 Sims and Overcash [13]

Preparation of Soil Microcosms

A bulk sample of sandy loam (Kidman) was obtained from a Utah state University agricultural experiment station in Kaysville, Utah. The soil had been fallow for approximately 3 years. Prior to use in the study, the soil was air dried and screened to $<2 \mathrm{~mm}$. Soil properties determined prior to initiation of the study include a soil $\mathrm{pH}$ of $7.9,0.5 \%$ by weight organic carbon, $0.06 \%$ by weight total phosphorus, $0.07 \%$ by weight total nitrogen and a water holding capacity of $16 \%$ by weight. Microcosms consisted of $20 \mathrm{~g}$ of soil in $250 \mathrm{~mL} g l a s s$ beakers and a glass rod for mixing added materials with the soil. Each beaker was capped with polyethylene film (Glad Wrap; Dow Chemical Co.) to reduce moisture loss during incubation. Initial soil respiration rates (data not shown) indicated that the high oxygen permeability of the polyethylene film (316 $\mathrm{cm}^{3} / 645 \mathrm{~cm}^{2} / 24 \mathrm{hr}$ ) and periodic removal of microcosm covers to replenish soil moisture would ensure that oxygen levels in the soil remained high during incubation.

To initiate incubation the moisture content of each microcosm was adjusted to $16 \%$ with deionized water. The microcosms were capped with polyethylene film and placed in incubation chambers at temperatures of $10 \pm 2,20 \pm 2$, or $30 \pm 2{ }^{\circ} \mathrm{C}$. After a 10 day incubation period, $2 \mathrm{~mL}$ of the $16 \mathrm{PAH}$ standard solution were added to each microcosm and thoroughly mixed with the soil using glass stirring 
rods. The microcosms were left open to the atmosphere at $20 \pm 2^{\circ} \mathrm{C}$ to permit the carrier solvent to evaporate before remoistening the soil and capping the beakers. During incubation, water was periodically added to each microcosm to compensate for evaporative losses. The moisture content of the soils was maintained between 80 and 100 o of the soil water holding capacity. The duration of the degradation experiment was 240 days during which soil microcosms were sampled at times 0,10 , and 60 days and thereafter every 30 days to the end of the study.

\section{Extraction and Analysis}

All glassware was washed with soap and water, rinsed with deionized water, and muffled at $550^{\circ} \mathrm{C}$ prior to use.

Soil microcosms at each temperature were periodically sampled in triplicate and prepared for extraction by removing the polyethylene covers and permitting the soil to air dry for 18-24 hours. The Tissumizer (Tekmar; Cincinnati, OH) homogenization system used for the soil extractions consisted of the Model SDT-1810 motor, Model SDT-182EN shaft and generator assembly, and Model TR-10 speed controller. The $20 \mathrm{~g}$ of soil in each microcosm was homogenized for 45 seconds in the original microcosm beaker with $140 \mathrm{~mL}$ of HPLC grade dichloromethane. After permitting the solids to settle in the beaker, the supernatant was transferred to a Gelman stainless steel pressure filter fitted with a whatman GF/D glass fiber filter. The solids were reslurried with $40 \mathrm{ml}$ of solvent and transferred with rinsing to the pressure filter. Extract solution was pressure filtered into a $600 \mathrm{~mL}$ glass beaker and transferred to a drying column containing $40 \mathrm{~g}$ of anhydrous $\mathrm{Na}_{2} \mathrm{SO}_{4}$. The dried extract was concentrated in a Kuderna-Danish apparatus to a volume of approximately $0.5 \mathrm{~mL}$ and was brought to a final volume of 5 or $10 \mathrm{~mL}$ with HPLC grade acetonitrile for HPLC analysis.

The extracts were analyzed by reversed-phase HPLC using a Shimadzu Model LC-6A liquid chromatograph equipped with Model SCL-6A system controller, Model SIL-6A autosampler, Model C-R3A computing integrator and Model SPD-6A variable wavelength UV detector. Chromatography was performed on a $4 \mathrm{~mm} x 15 \mathrm{~cm}$ ODS column with 5u packing (SupelCo; LC-PAH). The gradient mobile phase program consisted of 2 minutes isocratic elution with $40 \%$ acetonitrile in water followed by 15 minutes linear gradient to $100 \%$ acetonitrile at a flow rate of $2 \mathrm{~mL} / \mathrm{min}$. PAHs were detected at $254 \mathrm{~nm}$.

\section{Statistical Analysis}

To obtain estimates of compound half life and evaluate the effect of temperature on apparent loss kinetics each data set was statistically analyzed using a zero and first order kinetic model. The model which best characterized the observed trend was selected on the basis of the least squares coefficient of determination and the reasonableness of the observed fit. Kinetic coefficients, represented by the least squares slope, were tested for significance (slope $\neq 0$ ) using the t-test. The confidence interval (95\%) for a given rate coefficient was used to estimate the confidence interval for the corresponding half life.

\section{RESULTS AND DISCUSSION}

\section{Results}

Apparent loss trends for naphthalene and acenapthylene were not characterized because of the rapid rate at which they disappeared from the soil during the first 60 days of the study. In Figures 1-14 are presented the apparent loss trends for the remaining 14 PAHs. The percentages of each compound 

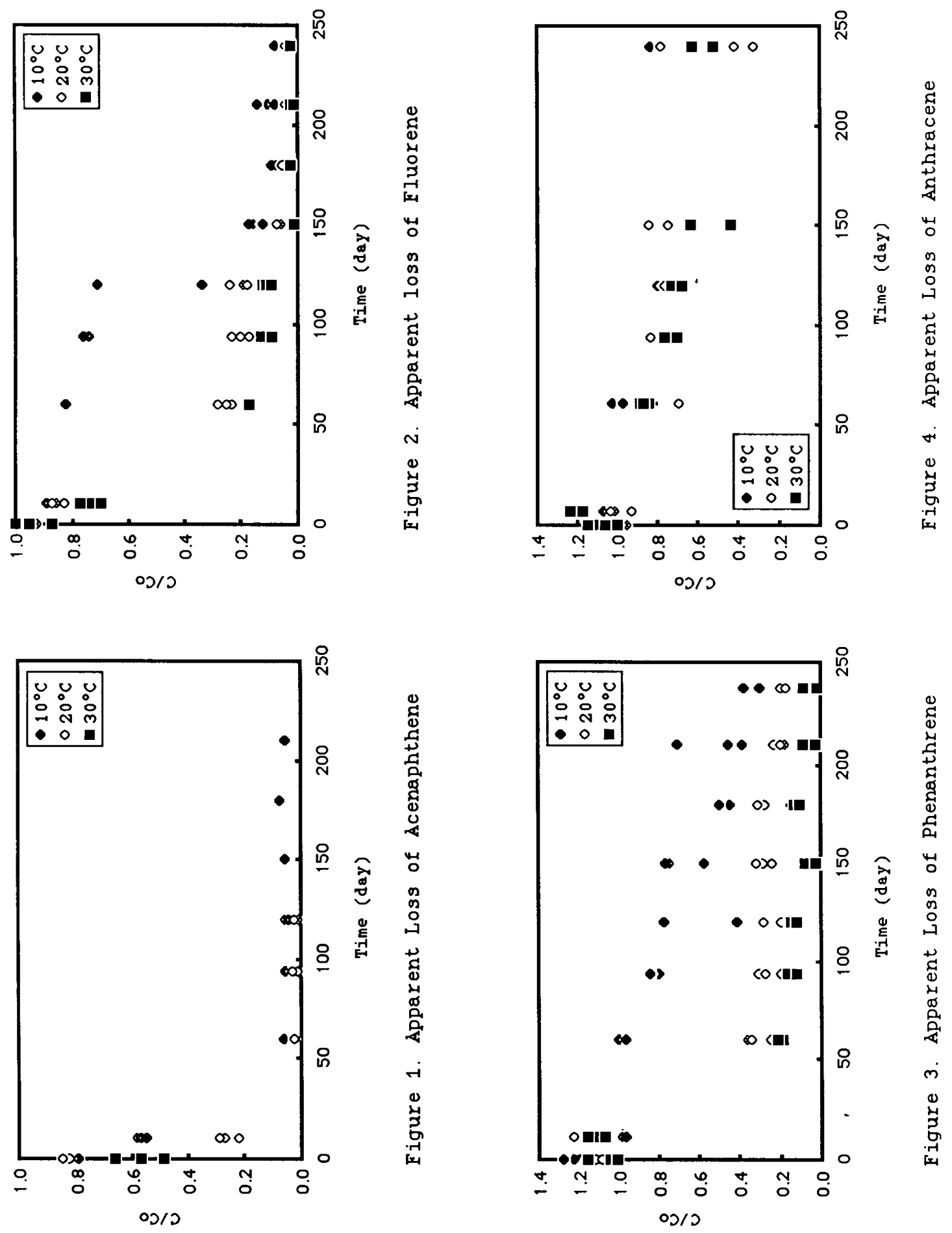

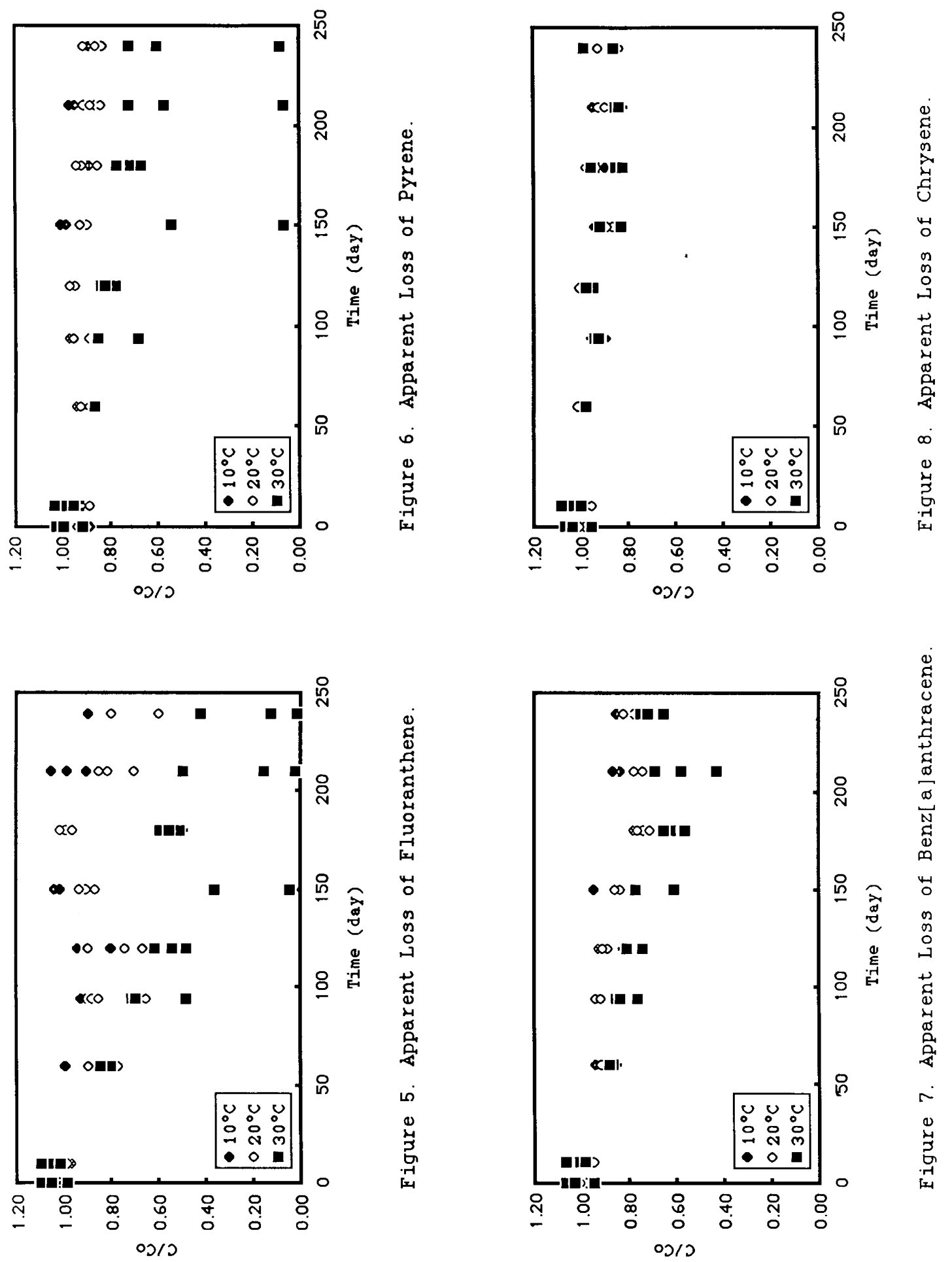

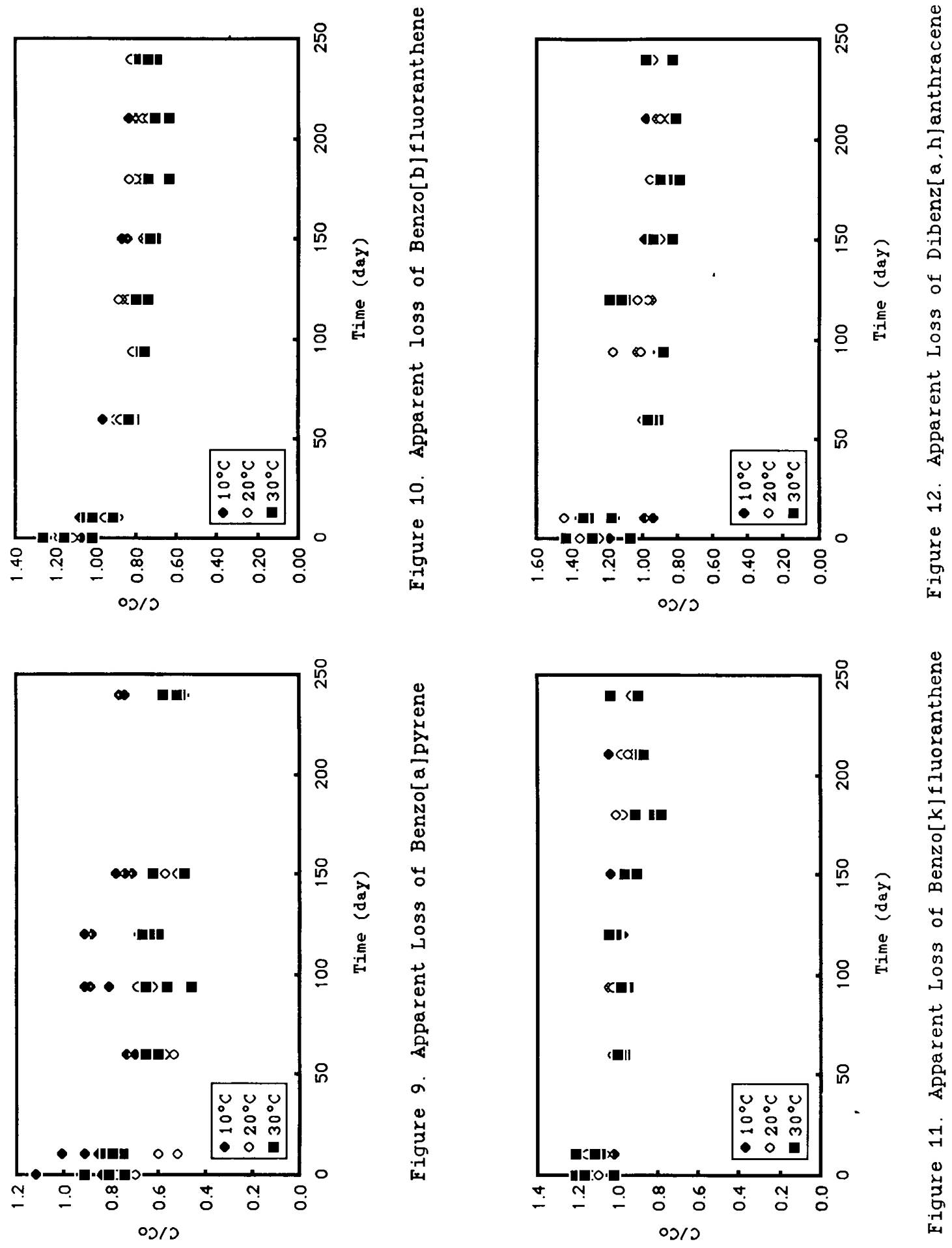


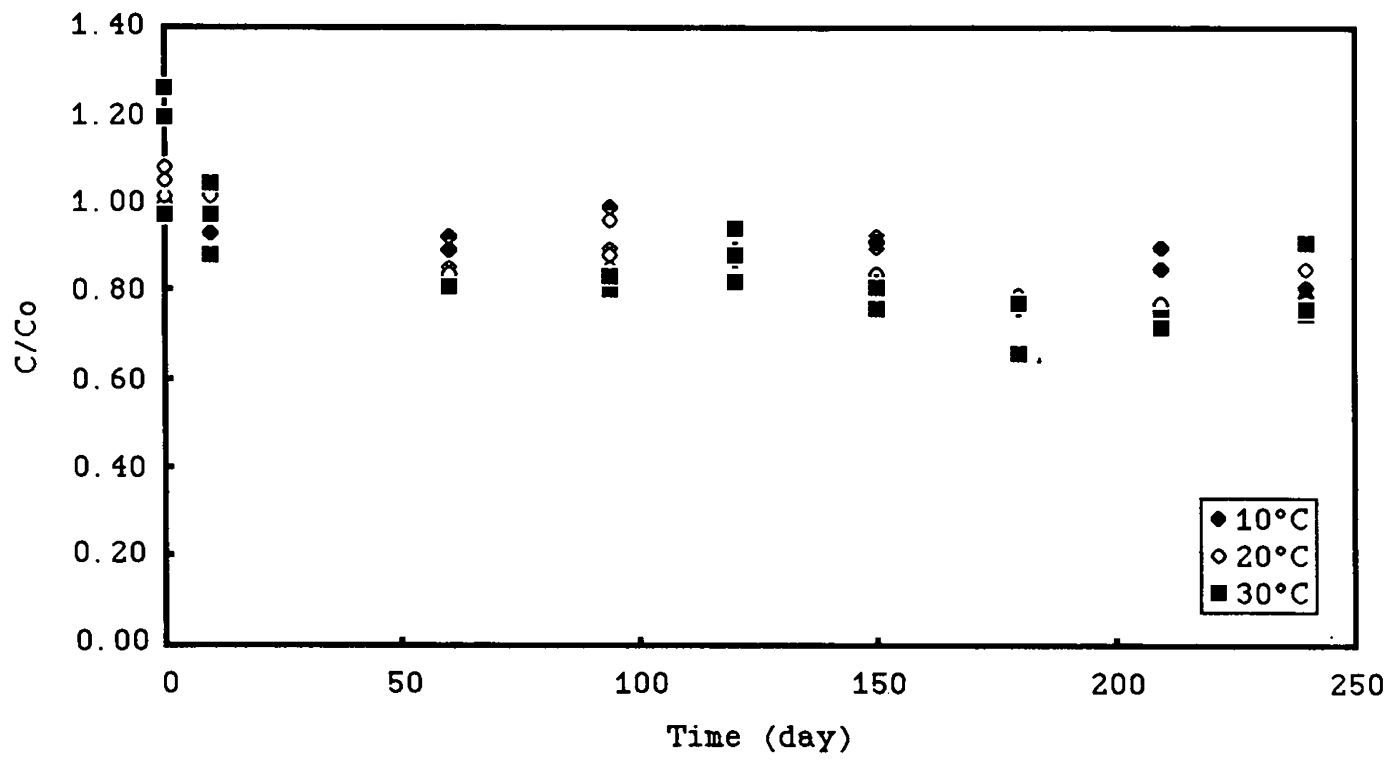

Figure 13. Benzo[g,h,i]perylene degradation.

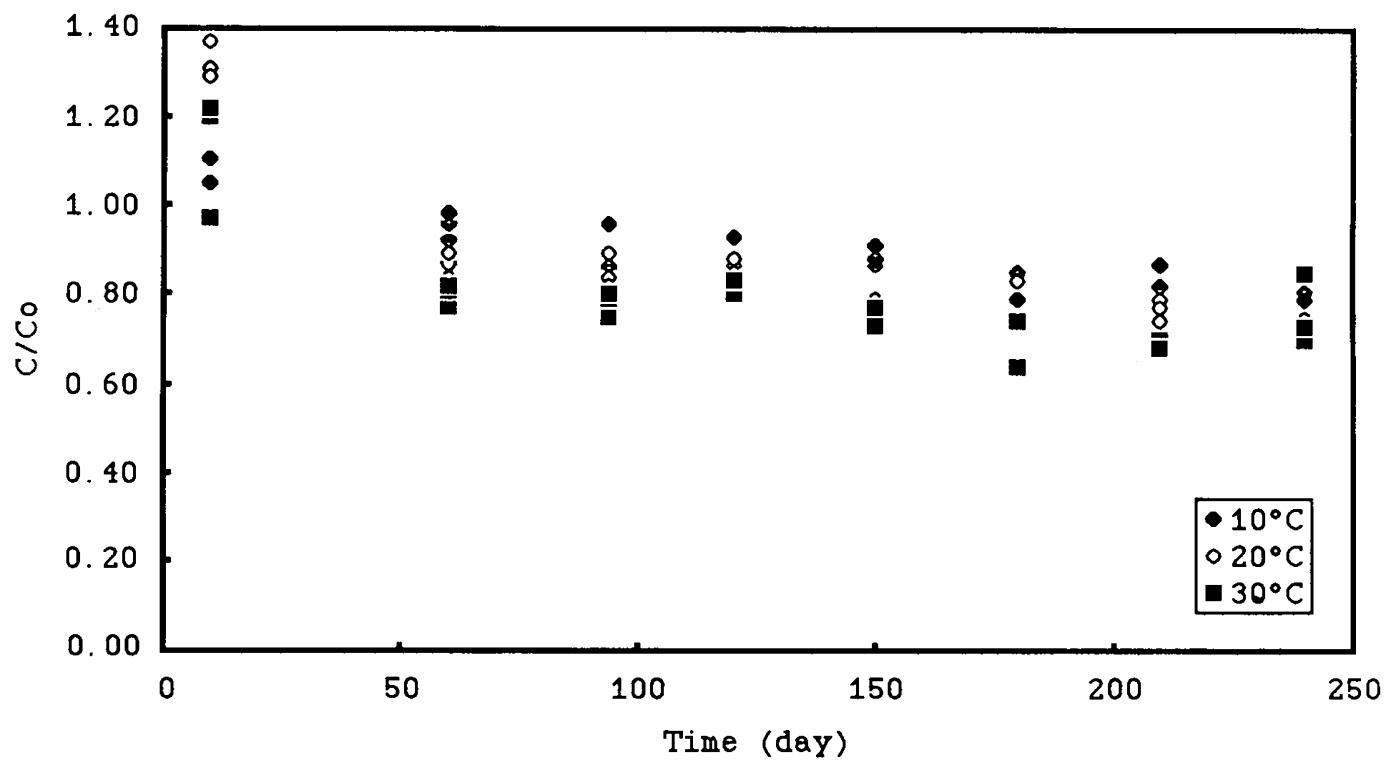

Figure 14. Indeno[123-c,d]pyrene degradation. 
in the soil at the end of the 240 day incubation period are presented in Table 2 along with estimated apparent loss half lives and representative half lives obtained from the literature.

Loss of acenaphthene, as shown in Figure 1, was rapid at all three temperatures. Half lives for acenaphthene are reported as less than either 10 or 60 days because rapid loss and limited sampling during this period precluded a more definitive estimate. At $10^{\circ} \mathrm{C}$ loss of acenaphthene could not be characterized with a single zero or first order model. Apparent loss trends for fluorene are presented in Figure 2. A first order model described the rate of fluorene loss at all three temperatures, and therefore first order rate coefficients were used for fluorene half life calculations. For phenanthrene a zero order model characterized the linear trend at $10^{\circ} \mathrm{C}$. Neither model was suitable for describing the apparent loss of phenanthrene at 20 and $30^{\circ} \mathrm{C}$ as each underestimated loss during the early period of the study and overestimated loss towards the end of the 240 day incubation period. Half lives for phenanthrene at 20 and $30^{\circ} \mathrm{C}$ were therefore estimated to be less than 60 days as indicated by the apparent loss trends in Figure 3. For the compounds anthracene, fluoranthene, pyrene, and benz[a] anthracene a zero order decay model was appropriate for characterizing the observed apparent loss trends. At $10^{\circ} \mathrm{C}$, however, negligible loss of fluoranthene and pyrene was indicated, because slopes of the decay curves were statistically equivalent to zero. For the remaining five and six-ring compounds, little apparent loss was observed and the effect of temperature was negligible. In estimating the half lives for benzo[b]fluoranthene, dibenz[a,h]anthracene, benzo[g,h,i]perylene, and indeno $[1,2,3-c, d]$ pyrene the 0 and 10 day extraction results were not included in the least squares analysis as this data set did not fit the long term linear trends.

\section{Discussion}

In general the half lives of acenaphthene, fluorene, and phenanthrene at $20^{\circ} \mathrm{C}$ were comparable to values reported by other investigators but all other $\mathrm{PAH}$ were more recalcitrant than reported in the literature as shown in Table 2 . For several compounds the estimated half lives are extrapolations and serve to demonstrate the degree to which many of the compounds tended to persist in the soil. It has been demonstrated that natural soil microorganisms can degrade the PAHs benz[a]anthracene, benzo[a]pyrene, and dibenz[a,h]anthracene by cometabolic processes $[13,14,15]$. Thus the relative stability of the latter two compounds and other high molecular weight PAHs in this study suggests that the resident microbial distribution may not have included organisms capable of degrading these compounds or a suitable substrate was not present to stimulate cometabolic decomposition. The degradation of PAHs in soil to which a complex PAH containing waste has been added may demonstrate different apparent loss trends from what was observed in this study in which pure PAHs and no additional substrate matter were added.

The extent and rate of apparent loss was much greater for PAHs of low molecular weight and high aqueous solubility as demonstrated in Table 2 . Substantial loss of the three-ring compounds acenaphthene, fluorene, and phenanthrene was observed at all temperatures during the course of the study. Comparatively reduced in both rate and extent were apparent losses of anthracene, another three-ring compound and the four-ring compounds fluoranthene, pyrene, and B[a]A. Loss of chrysene, a four-ring compound, and the remaining five and six-ring compounds was minimal at all three temperatures. Bossert et al. [4] found similarly that after a 1280 day laboratory simulation of the land treatment process the total remaining of three-ring, four-ring, five-ring, and six-ring PAHs was $1.4,47.4,78.5$, and $78.3 \%$ respectively. other investigators have noted this general trend for the PAH class of compounds $[6,13,16]$. Volatilization may have contributed significantly to the apparent losses of acenaphthene, fluorene, phenanthrene, and anthracene because Henry's 


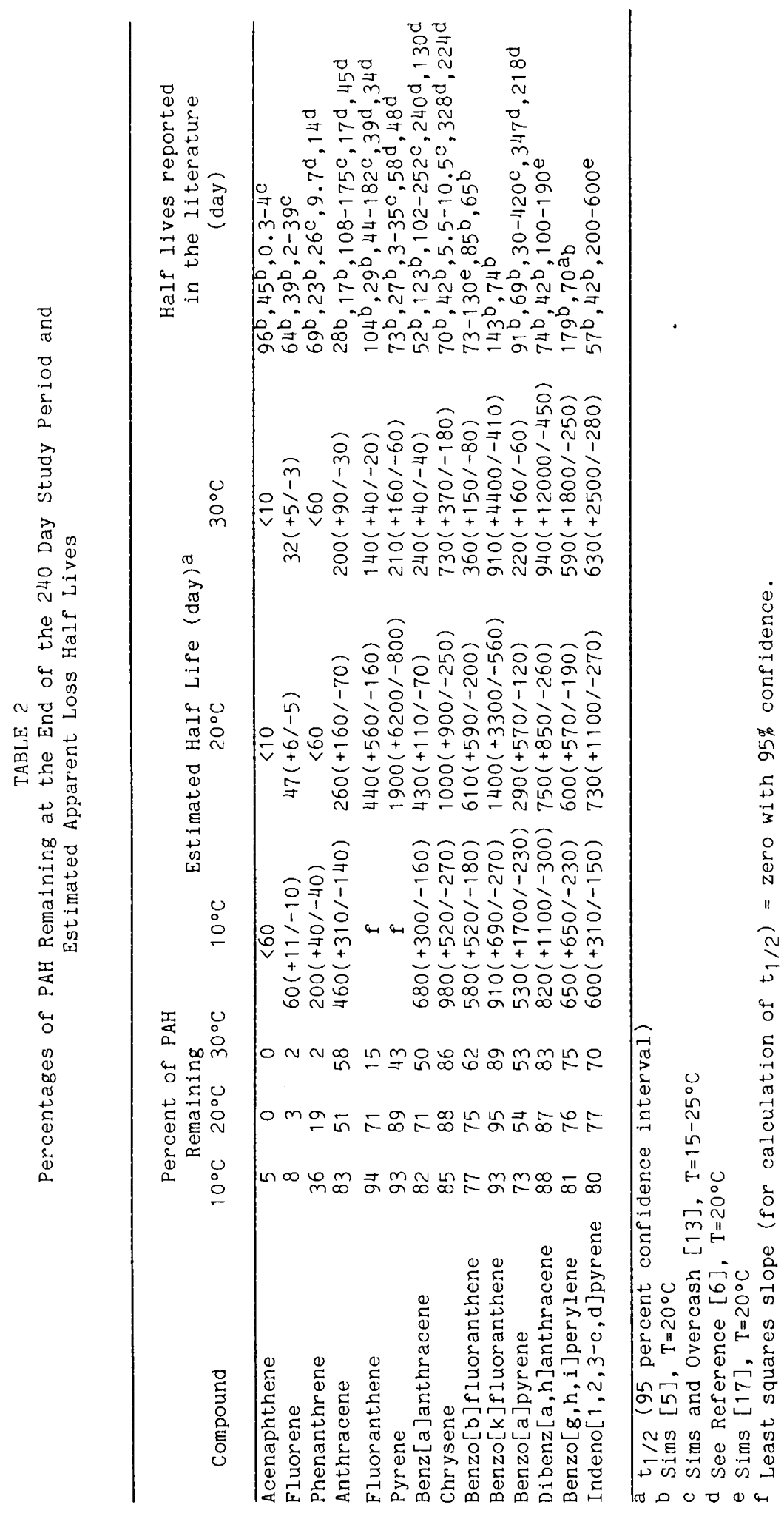


law coefficients (vapor pressure divided by aqueous solubility) for these compounds fall within the range $10^{-5}<\mathrm{H}<10^{-3} \mathrm{~atm} / \mathrm{mol} / \mathrm{m}^{3}$ cited by Lyman et al. [18] as a region for compounds of moderate volatility. Volatilization, either as parent compound or as metabolites, has been cited as a significant mechanism of anthracene loss from soil [6].

Unlike most of the observed trends, the apparent loss of phenanthrene at 20 and $30^{\circ} \mathrm{C}$ can be described as occurring in two phases between $0-60$ days and from 60 days to the end of the study. During the interval between 0 and 60 days the loss of phenanthrene at the two higher temperatures occurred at a relatively rapid pace which could not be characterized, but from 60 days to the end of the study the rates were approximately linear and suggested a tendency for long term persistence of the compound in the soil. This indicates that conditions favorable for loss of the compound early in the incubation of the soil may have become less favorable during the latter stages of incubation. Similar trends have been observed by other researchers for the apparent losses of phenanthrene, anthracene, and fluoranthene in an agricultural sandy loam soil [6].

Increasing the soil temperature improved the rate and extent of apparent loss of low molecular weight PAHs but had little effect on loss of five and six-ring compounds as demonstrated in Figures 1-14 and Table 2. The effects of temperature on first order rate coefficients for loss of fluorene and zero order rate coefficients for loss of anthracene, fluoranthene, pyrene and Benz [a] anthracene were described by the Arrhenius equation $\left(\operatorname{Ln}(k)=-E_{a} / R T+\right.$ Ln (A), as demonstrated by the graph of $\ln (\mathrm{k}) \mathrm{vs}$. 1/T for these compounds in Figure 15. Arrhenius parameters for the apparent loss of the aforementioned compounds are summarized in Table 3. The applicability of these laboratory determined parameters to field conditions must be made with caution, because as noted by Dibble and Bartha [19], the mean of fluctuating temperatures in the field may not be equivalent to a constant incubation temperature of the same value in the laboratory. For phenanthrene an Arrhenius relationship was not observed indicating that another mathematical description of the temperature effect may require consideration in some cases.

There was appreciable loss of phenanthrene and other low molecular weight PAHs at $10^{\circ} \mathrm{C}$ which is probably a lower temperature boundary for most land treatment operations in temperate regions. Thus loss of these compounds may be expected to occur at treatment facilities during the cool winter months.

TABLE 3

Arrhenius Parameters for the Apparent Loss of Fluorene, Anthracene, Fluoranthene, Pyrene, and Benz[a] anthracene

\begin{tabular}{lcc} 
Compound & $\begin{array}{c}\text { Activation Energy } \\
(\text { Kcal/mel) }\end{array}$ & $\begin{array}{c}\text { Preexpontial } \\
\text { Term Ln(A) }\end{array}$ \\
\cline { 2 - 2 } Fluorene & 5.0 & 4.5 \\
Anthracene & 7.5 & 12.9 \\
Fluoranthene & 21.7 & 36.3 \\
Pyrene & 40.3 & 67.0 \\
Benz[a] anthracene & 9.4 & 12.8
\end{tabular}

1 A has units of $\mu \mathrm{g} / \mathrm{g} / \mathrm{d}$ for the zero order model and $\mathrm{d}^{-1}$ for the first order model. 


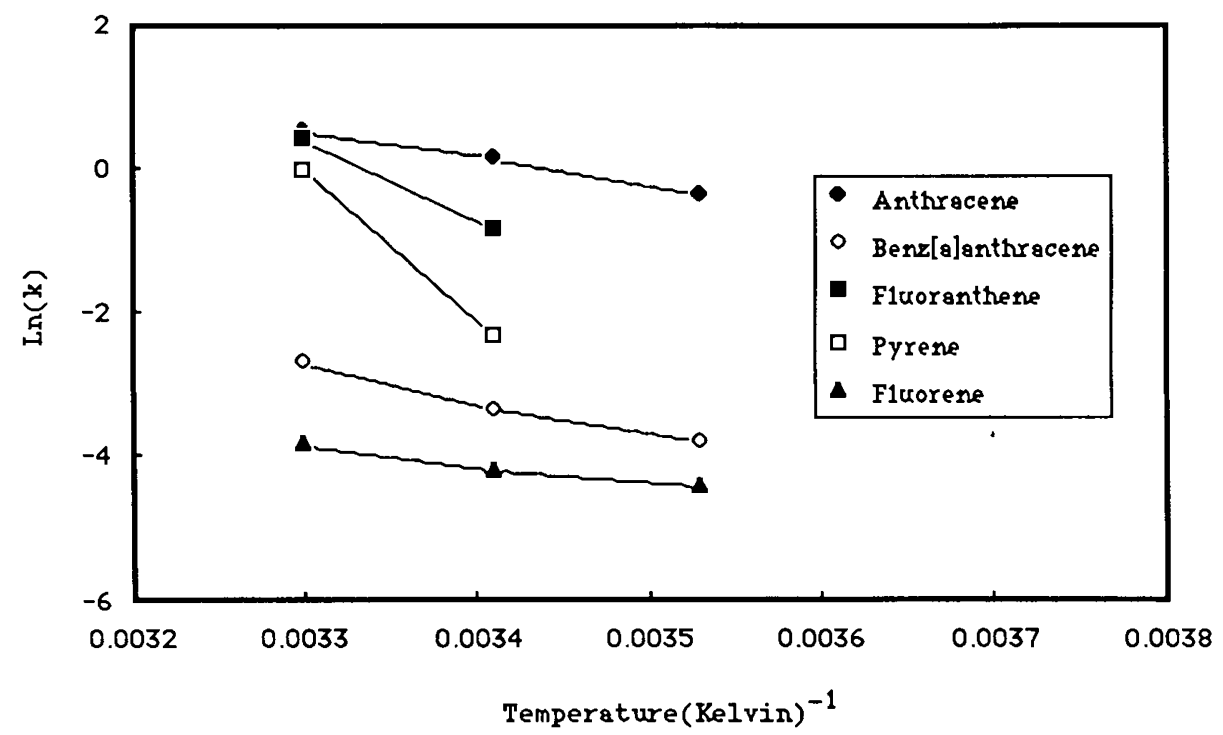

Figure 15. Arrhenius Plot of Zero Order Apparent Loss Rate Coefficients for Anthracene, Benzla]anthracene, Fluoranthene, and Pyrene. First order Rate Coefficients Are Plotted for Fluorene.

\section{CONCLUSIONS}

The extent and rate of low molecular weight $\mathrm{PAH}$ loss increased with increasing soil temperatures, but there was very little apparent loss and therefore little effect of temperature on loss of five and six-ring PAHs. Appreciable loss of low molecular weight PAHs was observed even at $10^{\circ} \mathrm{C}$ which is probably a lower temperature boundary for most land treatment operations in temperate regions. Under some conditions the Arrhenius expression may be appropriate for describing the effect of temperature on PAH apparent loss rates in soil.

The results of this and other studies suggest that under certain soil conditions the high molecular weight paHs have the potential to persist for considerable periods of time and therefore have the potential to accumulate following repeated addition of PAH-containing wastes in land treatment systems. After 240 days of incubation, phenanthrene, a readily degradable $P A H$, remained in the soil at a concentration of $200 \mu \mathrm{g} / \mathrm{g}$ at $20^{\circ} \mathrm{C}$ indicating that under closure conditions the lower molecular weight PAHs may also be persistent. Thus measures should be investigated to ensure the degradation of the more recalcitrant PAHs during the active period of a land treatment system and management options should be developed to ensure continued degradation of all paHs once waste applications have ceased.

\section{ACKNOWLEDGMENTS}

This work was sponsored by the U.S. Environmental Protection Agency, Robert S. Kerr Environmental Research Laboratory, Ada, OK under cooperative agreement number CR-810979-02. The project officer was John E. Matthews. This work has not been subjected to the Agency's peer review and therefore does not necessarily reflect the views of the Agency, and no official endorsement should be inferred. 
1. "Permit Guidance Manual on Hazardous Waste Land Treatment Demonstrations", Final Draft, Office of Solid Waste, U.S. Environmental Protection Agency, EPA 530/SW86-032, 1986.

2. "Hazardous Waste Management System: Permitting Requirements for Land Disposal Facilities", Federal Register, 47, 1982, 32324.

3. Loehr, D.C., Land Treatment: A Waste Management Alternative, Loehr, R.C. and Malina, J.F., Eds., University of Texas Center for Research in Water Resources, Austin, 1986, 7.

4. Bossert, I., Kachel, W.M., and Bartha, R., Appl. and Environ. Microbiol., 47, 763 (1984).

5. Sims, R.C., Land Treatment: A Waste Management Alternative, Loehr, R.C. and Malina, J.F., Eds., University of Texas Center for Research in Water Resources, Austin, 1986, 151.

6. "The Persistence of Polynuclear Aromatic Hydrocarbons in Soil", Petroleum Association for Conservation of the Canadian Environment, Ottawa, Ontario, Report No. 85-2, 1985.

7. Ryan, J., Land Treatment: A Waste Management Alternative, Loehr, R.C. and Malina, J.F., (Eds.), University of Texas Center for Research in Water Resources, Austin, 1986, 347.

8. Hamaker, J.W., Organic Chemicals in the Soil Environment, Vol. 1, Goring, C.A.I. and Hamaker, J.W., Marcel Dekker, Inc., New York, $1972,253$.

9. Smith, O.L., Soil Microbiology: A Model of Decomposition and Nutrient Cycling, M. J. Bazin (Ed.), CRC Press, Inc., Boca Raton, 1982, 161.

10. Parker, L.W. and Doxtader, K.G., J. Environ. Qual., 12, 553, (1983)

11. Walker, A., J.Environ. Qual., 3, 396, (1974)

12. U.S.EPA., Soil-Waste Treatability Studies, Vol 1, Waste Characterization and Loading Rate Determination, and Vol 2, Degradation, Transformation, and Immobilization of Waste Constituents, Robert S. Kerr Environmental Research Laboratory, U. S. Environmental Protection Agency. Cooperative Agreement No. CR-810979, 1986.

13. Sims, R.C., and Overcash, M.R., Residue Reviews, 88, 1 (1983).

14. Herbes, S.E., Appl. and Environ. Microbiol., 41, 20, (1981).

15. McKenna, E.J., Biodegradation of polynuclear aromatic hydrocarbon pollutants by soil and water microorganisms. Presented at the 70 th annual meeting of the American Institute of Chemical Engineers, - Nov. 13-17, New York, (1977).

16. Herbes, S.E., and Schwall, L.R., Appl. and Environ. Microbiol., 35, 306 (1978).

17. Sims, R.C., Land treatment of polynuclear aromatic compounds, PhD dissertation, North Carolina State University, Raleigh, 1982. 
18. Lyman, W.J., Rechl, W.F., and Rosenblatt, D.H., Chemical Property Estimation Methods, McGraw-Hill, New York, 1982.

19. Dibble, J.T., and Bartha, R., Appl. and Environ. Microbiol.,37, 729 (1979).

Ronald C. Sims Utah water Research Laboratory Utah State University Logan, UT 84322-8200 
This article has been cited by:

1. JUDITH L. SIMS, RONALD C. SIMS, JOHN E. MATTHEWS. 1990. Approach to Bioremediation of Contaminated SoilApproach to Bioremediation of Contaminated Soil. Hazardous Waste and Hazardous Materials 7:2, 117-149. [Abstract] [PDF] [PDF Plus] 